\title{
ABSORPTION AND SECRETION IN THE LARGE INTESTINE
}

\author{
R. SHIELDS, F.R.C.S. J. B. MiLES, F.R.C.S.
}

Department of Surgery, Welsh National School of Medicine and United Cardiff Hospitals, Cardiff.

THE ABSORPTIVE function of the colon is confined to transforming the fluid chyme, received from the ileum, into a semi-solid mass. Our knowledge of this function has been largely inferred, by comparing the volume and content of the discharges from well-established ileostomies with the composition of the fæces of normal subjects (Table 1). From these data it is evident that the colon absorbs water, sodium and chloride and secretes potassium. In addition, bicarbonate ions are secreted into the colonic lumen (d'Agostino, Leadbetter and Schwartz, 1953).

The means by which the colon absorbs and secretes water and electrolytes have been elucidated in a series of animal experiments both in vivo and in vitro. Sodium has been shown to be actively absorbed by the colon of the rat (Curran and Schwartz, 1960), of the dog (Cooperstein and Brockman, 1959) and of the bull-frog (Chalfin, Cooperstein and Hogben, 1958; Cooperstein and Hogben, 1959). In these species, chloride absorption was shown to be entirely passive in nature. Potassium may be secreted passively into the colonic lumen to maintain the electrical neutrality, disturbed by the active movement of sodium ions in the opposite direction; or a coupled sodiumpotassium pump may exist in the colon, actively transferring sodium ions from lumen to blood, and potassium ions in the opposite direction (Ussing, 1960). The type of transport system employed by the colon in water absorption remains obscure. One widely-held view is that water movement is passive and secondary to the transfer of solute-solute is absorbed, and water follows in response to the osmotic gradient set up (Curran and Schwartz, 1960). Many observations, however, particularly from in vitro experiments (for review, Shields, 1964), suggest that water may be actively transported by the intestine. Indeed, several mechanisms may be used in the absorption of water.

There have been few reported studies on the absorption and secretion of water and electrolytes in the human large intestine. Early workers (Annis and Alexander, 1952; Parsons, Powell and Pyrah, 1952) showed that the colon absorbed sodium, chloride and water, and secreted potassium. In these experiments, however, only the net movements of water and electrolytes were measured. These substances are simultaneously exchanged in both directions across the intestinal mucosa (Visscher, Fetcher, Carr, Gregor, Bushey and Barker, 1944a; Visscher, Varco, Carr, Dean and Erickson, 1944b). When the amount of a substance moving from the bowel/lumen into the body is greater than that moving in the opposite direction, the resultant or net movement is said to be 'absorption' whereas, when the amount moving from the body into the bowel lumen is greater than that moving in the opposite direction, the resultant, or net movement, is 'secretion'. The semantics of intestinal transport? have been discussed elsewhere (Shields, 1964).

Within the last two years there have been several attempts to study this exchange of water and electrolytes across the colonic mucosa. Duthie and Atwell (1963) confirmed the bidirectional transport of water, sodium and potassium in segments of human colon, temporarily isolated during operation. However, some of our own experiments suggest that surgical trauma can alter the intestinal handling of sodium and potassium (Shields, 1965). Levitan, Fordtran, Burrows and Ingelfinger (1962) measured, in the intact colon of unanæsthetised subjects, the bidirectional movement of water, the net absorption of sodium and chloride, and the net secretion of potassium and bicarbonate. They introduced a tube, passed by mouth, into the crcum. The entire length of colon was perfused with a test solution and the perfusate was collected by a tube inserted through the anus into the rectum. However, there have been no previous studies reported, in which the bidirectional movements of sodium, potassium and water have been simultaneously studied in the human colon of unanæsthetised subjects.

To this end we have developed further the 
TABLE 1

The Composition of THE Dejecta of Established Ileostomies and OF THE FAeces OF NORMAL SUbJects ${ }^{+}$

\begin{tabular}{l|c|c}
\hline & $\begin{array}{c}\text { Composition of dejecta } \\
\text { of established ileostomies }\end{array}$ & $\begin{array}{c}\text { Composition of faeces } \\
\text { of normal subjects }\end{array}$ \\
\cline { 2 - 3 } Weight (g.) & 466 & 150 \\
Volume (ml.) & $400-500$ & 100 \\
Sodium - concentration++ & $115-145$ & $25-50$ \\
Potassium-concentration++ & 53 & $2.5-5.0$ \\
Chloride-concentration++) & $6--30$ & $80-132$ \\
-daily loss (mEq.) & $75-100$ & $10-13$ \\
& $35-50$ & $1-50$ \\
\hline
\end{tabular}

+-Data from Davenport, (1961) Wells (1962), and Kanaghinis, Lubran and Coghill (1963)

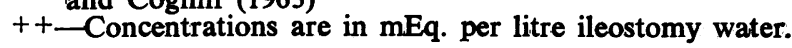

TABLE 2

The Rates of Movement of Sodium, Potassium and Water into and OUT OF THE LUMEN OF THE INTACT COLON OF FOUR NORMAL SUBJECTS

\begin{tabular}{l|c|c}
\hline Substance & Direction & Mean rate \pm standard deviation \\
\hline Sodium & $\begin{array}{c}\text { out of colon } \\
\text { into colon } \\
\text { absorption }\end{array}$ & $0.61 \pm 0.09$ \\
(mEq. per minute) & $0.29 \pm 0.08$ \\
Potassium & $0.32 \pm 0.09$ \\
out cf colon & $\begin{array}{c}\text { into colon } \\
\text { secretion }\end{array}$ & $0.018 \pm 0.005$ \\
Water & $0.040 \pm 0.01$ \\
(ml. per minute) & $\begin{array}{c}\text { out of colon } \\
\text { into colon }\end{array}$ & $0.022 \pm 0.01$ \\
& absorption & $7.5 \pm 1.1$ \\
\hline
\end{tabular}

method of Levitan and others (1962). The test solution was Tyrode's solution containing radioactive sodium and potassium, and the stable isotope of water, deuterium oxide. Polyethylene glycol (molecular weight, 4,000) was added to the perfusing solution as a nonabsorbable marker. This test solution was perfused through the colon by means of a peristaltic pump at a constant rate of $20 \mathrm{ml}$./ minute. The details of the method and of the calculations are given elsewhere (Miles and Shields, 1965).

The results confirm that the human colon absorbs water and sodium and secretes potassium, and that these net movements are incorporated in a much more rapid two-way traffic across the intestinal mucosa (Table 2). Thus, the large intestine handles a greater quantity of water and electrolytes than is immediately apparent from comparing the amount of fluid that enters the colon at one end with that which is expelled at the other. Of particular interest is the fact that the movement of sodium into the body from the bowel lumen is more than twice that moving in the opposite direction. Such a finding 9 s in general agreement with animal studiês (Visscher and others, 1944b) that the col8n is an extremely efficient absorber of sodiuth ions. Nevertheless more sodium and, of courses, water are absorbed, albeit less efficiently, gin the small intestine since the latter presentso a larger total surface area.

Such direct measurement of the exchange: fluid and electrolytes across the colonic mucosa permits a more accurate and meaningful assessment of colonic function. Although these studies were confined to three or four hougs, 


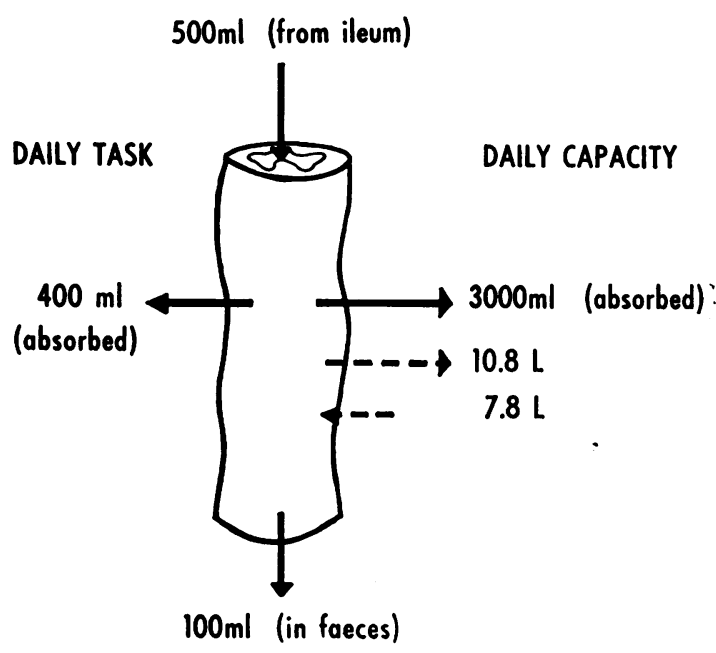

FIG. 1.-Water absorption in the colon. The values for the daily work performed by the colon are obtained from the data in Table 1 . The values for the total functional capacity of the colon are derived from the data in Table 2 .

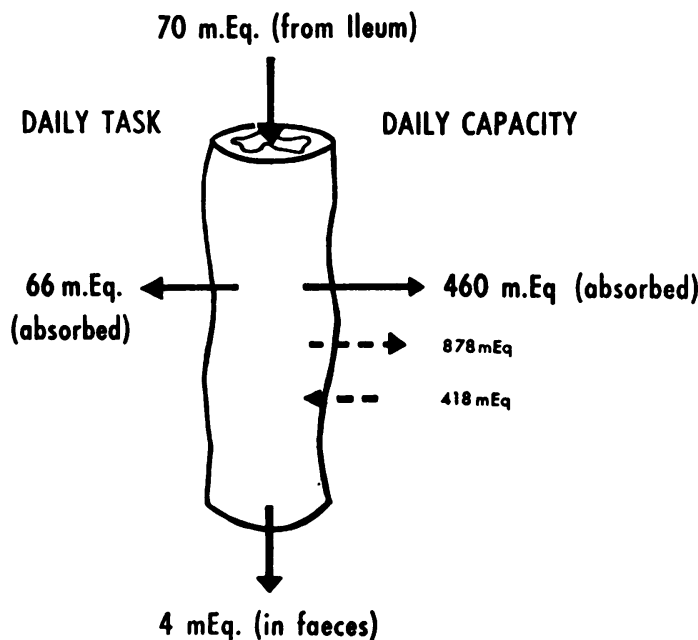

FIG. 2.-Sodium absorption in the colon. The values for the daily work performed by the colon are obtained from the data in Table 1 . The values for the total functional capacity of the colon are derived from the data in Table 2.

the colon did not show any change in its behaviour during this time. If the colon maintained these rates of movement for 24 hoursand there would seem little objection to this assumption - then it would absorb 3 litres of water and $460 \mathrm{mEq}$. of sodium, and secrete $32 \mathrm{mEq}$. of potassium (Figs. 1, 2 and 3). Thus, although the colon is called upon to absorb

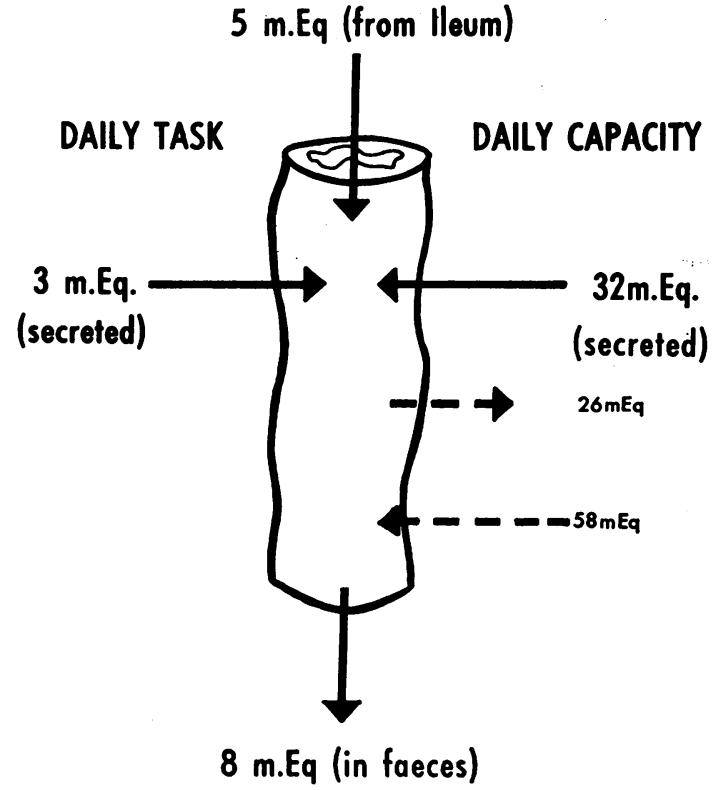

FIG. 3.-Potassium secretion in the colon. The values for the daily work performed by the colon are obtained from the data in Table 1. The values for the total functional capacity of the colon are derived from the data in Table 2 .

only $400 \mathrm{ml}$. water each day, it has a capacity to absorb seven times this amount, and, in doing so, will handle over 18 litres of fluid10.8 litres leaving, and 7.8 litres entering, its lumen. Similarly, the reserve capacity of the colon for sodium absorption is almost seven times the work that it is called upon to perform. Finally the daily loss of potassium from the body by colonic secretion is low, but, if the colonic lumen were perfused continuously, then the rate of potassium secretion would be greatly accelerated.

Several important conclusions can be drawn from these observations. First, despite the reserve capacity of the colon, there is a definite limit to the extent to which the colon can compensate for a loss in absorptive function of the small intestine. Secondly, if the ability of the colon to handle water and electrolytes is impaired then mainly small bowel content will be lost from the body. Third, even although the colon has preserved its normal absorptive ability, and only the small intestine is diseased. then the passage of increased quantities of fluid over the colonic mucosa will bring about increased secretion of potassium ions by the colon. Abnormal losses of potassium have been demonstrated with the over-use of laxatives (Coghill, McAllen and Edwards, 1959). 
There is some evidence that the absorptive function of the colon may be modified in response to the body's needs. It has been known for some time that, with salt deprivation, sodium almost entirely disappears from the faces (Field, Swell, Dailey, Trout and Boyd, 1955). We have recently re-investigated this problem in dogs, and have shown that the colon increased the rate of sodium absorption by reducing the amount of sodium it allows to 'leak' back into its own lumen. (Clarke and Shields, 1963). Such intestinal conservation of sodium is brought about at the expense of increased potassium secretion. Since sodium depletion is a powerful stimulus to the secretion of aldosterone, we investigated the effects of aldosterone infusions upon isolated segments of colon in both man and the dog (Shields and Elmslie, 1962). The intestinal handling of potassium ions was influenced by aldosteronepotassium secretion was increased significantly because more potassium ions entered the intestinal lumen. This action of aldosterone upon the intestine was blocked by spironolactone (Elmslie, Mulholland and Shields, 1965). In addition, using the technique of colonic perfusion, we have shown that, in primary hyperaldosteronism, there is an increased loss of potassium from the colon, because the bowel allows more potassium ions to enter than under normal conditions (Miles and Shields, 1965). The altered handling of potassium by the colon is reversible, returning to normal with the removal of the tumour.

With these refined techniques it is now possible to characterise fully the disturbances in colonic function when the colon itself is diseased. In their pioneer investigations, Duthie and his colleagues (Duthie and Atwell, 1963; Duthie, Watts, de Dombal and Goligher, 1964) have shown that the colon's ability to handle water and electrolytes is disturbed in villous papillomatosis and ulcerative colitis. Unfortunately these studies, using isolated segments of bowel investigated at operation, permit only one measurement in each patient. Nevertheless, much interesting information has been obtained -for example, that the excessive losses of fluid from a segment of bowel containing a villous papilloma is caused by the cells composing the tumour being intrinsically different from normal colonic mucosal cells. We are engaged in similar studies of the diseased colon, employing, however, the technique of colonic perfusion so that several estimations may be made upon the same patient and so, in this way, the effect of drugs and various forms of treatment, surgical and medical, may be assessed.
J. B. Miles is in receipt of a full-time grant from the Medical Research Council.

\section{REFERENCES}

ANNIS, D. and AleXander, M. K. (1952): Different局 Absorption of Electrolytes from the Large Bowel in Relation to Ureterosigmoid Anastomosis, Langst, ii, 603.

d'Agostino, A., LeadbetTer, W. F., and SChWar W. B. (1953): Alterations in the Ionic Compositian of Isotonic Saline Solution Instilled into the Colon. J. clin. Invest., 32, 444.

Chalfin, D., CoOperstein, I. L. and Hogbea, C. A. M. (1958): Fluid and Electrolyte Movement across Intestinal Wall of Bull Frog. Proc. $S \overrightarrow{Q G}$. exp. Biol. (N.Y.), 99, 746.

Clarke, A. M., and Shields, R. (1963): The Roleक्षf the Intestine in Fluid and Electrolyte Conservatien during Sodium Depletion. Brit. J. Surg., 50, 768:

Coghill, N. F., McAllen, P. M., and Edwards,. $\mathbf{F}$. (1959): Electrolyte Losses Associated with the Taking of Purges Investigated with Aid of Sodiunn and Potassium Radioisotopes. Brit. med., J., i, tu.

CoOPERSTEIN, I. L., and BrockMan, S. K. (1959\%: The Electrical Potential Difference Generated Gy the Large Intestine; its Relations to Electrolyte and Water Transfer. J. clin. Inv'est., 34, 435.

CoOperstein, I. L. and HoGben, C. A. M. (195\%: Ionic transfer across the Isolated Frog Large Intestine. J. gen. Physiol., 42, 461.

CuRran, P. F., and SchWARTZ, G. F. (1960): No영, and Water Transport by Rat Colon. J. gen. Phyid. 43, 555 .

DAvenPort, H. W. (1961): Physiology of the Digestive Tract. P. 221. Chicago: Year Book Publishess.

Duthie, H. L., and Atwell, J. D. (1963): The Absorption of Water, Sodium, and Potassium 9 an the Large Intestine with Particular Reference to the Effects of. Villous Papillomas. Gut, 4, 373.

Duthie, H. L., Watts, J. M., de Dombal, F. T., ä̊d Goligher, J. C. (1964): Serum Electrolytes a画 Colonic Transfer of Water and Electrolytes an Chronic Ulcerative Colitis. Gastroenterology, 48 , 525.

ElmSlie, R. G., Mulholland, A. T., and Shields, (1965): The Blocking by Spironolactone of ?he Action of Aldosterone Infusions upon the Intestimal Absorption of Water, Sodium and Potassiue Submitted for publication.

Field, H., Swell, L., Dailey, R. E., Trout, E. G. and BoYD, R. S. (1955): Electrolyte Changes In Ileal Contents and in Feces during Restriction ff Dietary Sodium With and Without the Administration of Cation-exchange Resin. Circulation, 12, 625.

Kanaghinis, T., Lubran, M., and COGHILl, N...T. (1963): The Composition of Ileostomy Fluid. God, $4,322$.

Levitan, R., Fordtran, J. S., Burrows, B. A., afid INGELFINGER, F. J. (1962): Water and Salt Absoption in the Human Colon. J. clin. Invest., 41, 1784.

Miles, J. B., and SHIELDS, R. (1965): The Movement of Water, Sodium and Potassium into and out $\$ f$ the Intact Human Colon. Submitted for publicgtion.

Parsons, F. M., Powell, F. J. M., and Pyrah, L. (1952): Chemical Imbalance following Ureterocofic Anastomosis. Lancet, ii, 559. 
Shields, R. (1964): Surgical Aspects of the Absorption of Water and Electrolytes by the Intestine. Monographs in the Surgical Sciences, 1, 119.

Shields, R. (1965): The Absorption and Secretion of Fluid and Electrolytes by the Obstructed Bowel, Brit. J. Surg. In the Press.

Shields, R., and Elmslie, R. G. (1962): The Effect of Aldosterone on Absorption of Water and Electrolytes from the Ileum and Colon of the Dog. Brit. J. Surg., 50, 96.

Ussing, H. H. (1960): I. The Alkali Metal Ions in Isolated Systems and Tissues. The Alkali Metal Ions in Biology. In Handbuch der experimentellen Pharmakologie, edited by $\mathrm{H}$. H. Ussing, P.
Kruhoffer, J. H. Thayson, and N. A. Thorn, p. 1. Berlin: Springer-Verlag.

Visscher, M. B., Fetcher, E. S., Carr, C. W., GREGOR, H. P., BUSHEY, M. S., and BARKER, D. E. (1944a): Isotopic Tracer Studies on the Movement of Water and Ions between Intestinal Lumen and Blood. Amer. J. Physiol., 142, 550.

Visscher, M. B., Varco, R. H., Carr, C. W., Dean, R. B., and ERICKSON, D. (1944b): Sodium Ion Movement Between the Intestinal Lumen and the Blood. Amer. J. Physiol., 141, 488.

Wells, B. B. (1962): Clinical Pathology, P. 541. Philadelphia and London: W. B. Saunders. 